\title{
Electrospray-Mass Spectrometric Analysis of Plasma Pyrophosphates Separated on a Multi-Modal Liquid Chromatographic Column
}

\author{
Su Hyeon Lee ${ }^{\text {a,b }}$, Jeongae Lee ${ }^{\mathrm{a}}$, Won-Yong Lee ${ }^{\mathrm{b}}$, Bong Chul Chung ${ }^{\mathrm{a}}$, and Man Ho Choi ${ }^{\mathrm{a}, *}$ \\ ${ }^{a}$ Future Convergence Research Division, Korea Institute of Science and Technology, Seoul 136-791, Korea \\ ${ }^{b}$ Department of Chemistry, Yonsei University, Seoul 120-749, Korea
}

Received December 8, 2011; Revised Decembere 14, 2011; Accepted December 15, 2011

First published on the web December 15, 2011; http://dx.doi.org/10.5478/MSL.2011.2.4.092

\begin{abstract}
Pyrophosphates are the key intermediates in the biosynthesis of isoprenoids, and their concentrations could reveal the benefits of statins in cardiovascular diseases. Quantitative analysis of five pyrophosphates, including isopentenyl pyrophosphate (IPP), dimethylallyl pyrophosphate (DMAPP), geranyl pyrophosphate (GPP), farnesyl pyrophosphate (FPP), and geranylgeranyl pyrophosphate (GGPP), was performed using liquid chromatography-tandem mass spectrometry (LC-MS/MS) in negative ionization mode. After dilution with methanol, samples were separated on a $3 \mu \mathrm{m}$ particle multi-modal $\mathrm{C}_{18}$ column $(50 \times 2 \mathrm{~mm})$ and quantified within $10 \mathrm{~min}$. The gradient elution consists of $10 \mathrm{mM}$ ammonium bicarbonate and $0.5 \%$ triethylamine (TEA) in water and $0.1 \%$ TEA in $80 \%$ acetonitrile was used at the flow rate of $0.4 \mathrm{~mL} / \mathrm{min}$. Overall recoveries were $51.4-106.6 \%$, while the limit of quantification was $0.05 \mu \mathrm{g} / \mathrm{mL}$ for GPP and FPP and $0.1 \mu \mathrm{g} / \mathrm{mL}$ for IPP, DMAPP, and GGPP. The precision (\% CV) and accuracy (\% bias) of the assay were $1.9-12.3 \%$ and $89.6-111.8 \%$, respectively, in $0.05-10 \mu \mathrm{g} / \mathrm{mL}$ calibration ranges $\left(\mathrm{R}^{2}>0.993\right)$. The devised LC-MS/MS technique with the multi-modal $\mathrm{C}_{18}$ column can be used to estimate the biological activity of pyrophosphates in plasma and may be applicable to cardiovascular events with cholesterol metabolism as well as the drug efficacy of statins.
\end{abstract}

Keywords: Pyrophosphate, Isoprenoids, LC-MS, Multi-modal column, Cardiovascular disease, Statins

\section{Introduction}

Intracellular mevalonate biosynthesis is an important metabolic pathway that produces many biomolecules that are essential for cell function, such as cholesterol and non-sterol isoprenoids. Cholesterol is an important end product that is not only a structural component of the membrane but also as the precursor for steroid hormones. ${ }^{1-3}$ The mevalonate pathway starts with three acetyl-CoAs, which are converted into 3-hydroxy-3methylglutaryl-CoA (HMG-CoA) and then mevalonate (MVA), which produces 5-pyrophosphomevalonate (MVAPP). After this step, they were metabolized into isopentenyl pyrophosphate (IPP), dimethylallyl pyrophosphate (DMAPP), geranyl pyrophosphate (GPP), farnesyl pyrophosphate (FPP), and then geranyl pyrophosphate (GGPP) through addition of IPP molecules. ${ }^{1-3}$ Statins as inhibitors are widely used to modulate the cholesterol levels in cardiovascular events mediated by decreasing the levels of isoprenoid intermediates like FPP and GGPP. ${ }^{4-6}$

Analytical methods for the detection of pyrophosphates have been developed ${ }^{6-8}$; however, due to their diverse chemical and physical properties, chromatography-based profiling has not been successfully achieved to date. ${ }^{6-9}$ Adequate retention was achieved under aqueous conditions, but it may not be selective enough and lead to co-elution, resulting in low

*Reprint requests to Dr. Man Ho Choi

E-mail:mh_choi@kist.re.kr sensitivity and mass spectrometric adulterations. Multi-modal liquid chromatographic column have a surface modification that allows multiple retention processes simultaneously for both cationic and anionic compounds as well as for polar compounds. Mixed stationary phases are attracted each other because of different polarity in a column and it utilizes secondary retention mechanisms maximized by controlling ionic strength of mobile phases. ${ }^{10,11}$

Here, we describe a comprehensive method using liquid chromatography-tandem mass spectrometry (LC-MS/MS) to allow for the direct detection and quantification of intermediates of the mevalonate pathway from IPP to GGPP. Chromatographic separation of five pyrophosphates was conducted using a multi-modal stationary phase $\mathrm{C} 18$ column that is LC-MS compatible for the analysis of polar compounds.

\section{Experimental Section}

\section{Chemicals}

Reference standards of five pyrophosphates including IPP, DMAPP, GPP, FPP, and GGPP, and thymolphthalein monophosphate disodium salt as an internal standard (ISTD) were obtained from Sigma (St. Louis, MO, USA). Sodium phosphate monobasic, sodium phosphate dibasic, and potassium carbonate were purchased from Sigma. All organic solvents were of analytical or LC grade and purchased from Burdick \& Jackson (Muskegan, MI, USA). 


\section{Standard solutions and quality-control samples}

Stock solutions of all reference standards were dissolved in $\mathrm{MeOH}: \mathrm{NH}_{4} \mathrm{OH}(7: 3, \mathrm{v} / \mathrm{v})$ at $1 \mathrm{mg} / \mathrm{mL}$, and working solutions were made up using methanol at concentrations of 0.01 $10 \mu \mathrm{g} / \mathrm{mL}$. All standard solutions were stored at $-20^{\circ} \mathrm{C}$ until needed. To optimize and validate the method, charcoal-stripped human plasma (HyClone, Logan, UT, USA) was first prepared as the isoprenoid-free sample based on a previous reports. ${ }^{12,13}$ The quality-control (QC) samples were prepared using pyrophosphate-free plasma spiked with five pyrophosphates at three different concentrations $(0.2,1$, and $5 \mu \mathrm{g} / \mathrm{mL})$.

\section{Sample preparation for the plasma pyrophosphates}

Plasma samples $(20 \mu \mathrm{L})$ were spiked with $20 \mu \mathrm{L}$ of thymolphthalein monophosphate as an internal standard and $10 \mu \mathrm{L}$ of $0.2 \mathrm{M}$ phosphate buffer ( $\mathrm{pH}$ 7.2). After dilution with $50 \mu \mathrm{L}$ of $\mathrm{MeOH}$, the sample was centrifuged on an Ultrafree-MC polyvinylidene fluoride (PVDF) membrane $(0.1 \mu \mathrm{m}$ pore size; Millipore) for $5 \mathrm{~min}$ at $14,000 \mathrm{rpm}$. Forty microliters of filtrate was subjected to LC-MS analysis in selected-reaction monitoring (SRM) mode.

\section{Instrumental conditions}

LC-MS analysis was performed with a Varian 212-LC system coupled to a 320-MS triple-quadrupole mass spectrometer (Varian, Walnut Creek, CA, USA). All pyrophosphates were separated using a Scherzo $\mathrm{SM} \mathrm{C}_{18}$ column $(50 \mathrm{~mm} \times 2 \mathrm{~mm}$ i.d., $3 \mu \mathrm{m}$ particle size; Imtakt Co., Kyoto, Japan) at $0.4 \mathrm{~mL} / \mathrm{min}$. After injection, the mobile phase consisting of A $(10 \mathrm{mM}$ $\mathrm{NH}_{4} \mathrm{HCO}_{3}$ and $0.05 \%$ triethylamine in water) and $\mathrm{B}(0.1 \%$ triethylamine in $80 \%$ acetonitrile) was controlled as follows: $0-1 \mathrm{~min}$ at $0 \% \mathrm{~B}$; $1-4 \mathrm{~min}, 0-60 \% \mathrm{~B} ; 4-7 \mathrm{~min}, 60-100 \% \mathrm{~B}$; 7$7.5 \mathrm{~min}, 100 \% \mathrm{~B}$; $7.5-8 \mathrm{~min}, 100-0 \% \mathrm{~B}$; and $8-10 \mathrm{~min}, 0 \% \mathrm{~B}$. The gradient was then returned to the initial condition $(0 \% \mathrm{~B})$ and held for 2 min before the next sample was run. All pyrophosphates were detected in negative ionization with their $[\mathrm{M}-\mathrm{H}]^{-}$ion as the precursor ion (Table 1). The mass spectrometer was operated under the following optimized conditions: a needle potential of $-5,000 \mathrm{~V}$, shield potential of $-600 \mathrm{~V}$, housing temperature of $55^{\circ} \mathrm{C}$, drying gas (nitrogen) temperature of $230^{\circ} \mathrm{C}$, drying pressure of $20 \mathrm{psi}$, nebulizing pressure (air) of $60 \mathrm{psi}$, and detector voltage of 1,400 V.

\section{Method validation}

The QC samples containing the pyrophosphates were quantified using the peak area ratios versus the corresponding ISTD for the pyrophosphates. Calibration samples were made up at 8 different concentrations (LOQ $\sim 10 \mu \mathrm{g} / \mathrm{mL}$ ), which depended on the sensitivity. The limits of detection (LOD) and quantification (LOQ) were defined as the lowest concentration with a signal-to-noise $(\mathrm{S} / \mathrm{N})$ ratio $>3$ and $>10$, respectively. Five samples at three different concentrations $(0.2,1$, and $5 \mu \mathrm{g} / \mathrm{mL})$ were analyzed. Precision and accuracy are expressed as the coefficients of variation $(\% \mathrm{CV})$ and percentage relative errors ( $\%$ bias), respectively. The intra- and inter-day assays were determined by the analysis of five replicates and the running of the samples on five different days.

The extraction recoveries were determined using the QC samples at three different concentrations by adding known amounts of analytes to the isoprenoid-free samples.

\section{Results and Discussion}

\section{Optimization of LC-MS/MS analysis}

Current advances in LC separation of polar compounds are driven by the requirement for high-throughput analyses with adequate resolution. The chromatographic separation of five pyrophosphates was conducted with a recently developed multi-modal stationary phase $3 \mu \mathrm{m}$ particle LC column for improving both throughput and sensitivity. Multi-modal column contains four different stationary ligands and it makes different retention behaviors of analytes compared to the mixed-mode columns which are simply embedded or tipped with reversedligand and either cation or anion exchange ligand. In initial study, the reversed-phase C18 column was eluted as broad peaks accompanied by too much short or long retention times along with organic solvent composition. In addition, overall retention for five pyrophosphates is altered by different $\mathrm{pH}$

Table 1. The LC-MS/MS information of pyrophosphates analyzed

\begin{tabular}{|c|c|c|c|c|c|c|}
\hline Compound & $\begin{array}{c}\text { Molecular } \\
\text { weight }\end{array}$ & Precursor ion & Product ion (CE) & $\begin{array}{c}\text { Needle } \\
\text { Potential } \\
\text { (V) }\end{array}$ & $\begin{array}{c}\text { Shield } \\
\text { Potential } \\
\text { (V) }\end{array}$ & $\begin{array}{c}\text { Capillary } \\
\text { Voltage }\end{array}$ \\
\hline Isopentenyl pyrophosphate (IPP) & 246.1 & $244.6[\mathrm{M}-\mathrm{H}]^{-}$ & $45.1, \underline{78.7}, 118.7,164.6$ & -4700 & -375 & -36 \\
\hline Dimethylallyl pyrophosphate (DMAPP) & 246.1 & $244.7[\mathrm{M}-\mathrm{H}]^{-}$ & $\underline{78.7}, 118.7,164.6$ & -3950 & -225 & -40 \\
\hline Geranyl pyrophosphate (GPP) & 314.2 & $312.8[\mathrm{M}-\mathrm{H}]^{-}$ & $\underline{78.7)}, 155.7,232.7$ & -4100 & -400 & -40 \\
\hline Farnesyl pyrophosphate (FPP) & 382.3 & $381.0[\mathrm{M}-\mathrm{H}]^{-}$ & $\underline{78.7}, 189.7,300.8,324.9$ & -4400 & -350 & -40 \\
\hline Geranylgeranyl pyrophosphate (GGPP) & 450.4 & $449.2[\mathrm{M}-\mathrm{H}]^{-}$ & 78.7, 118.6, 223.7, 369.0 & -4850 & -350 & -44 \\
\hline Thymolphthalein monophosphate (ISTD) & 554.5 & $509.2[\mathrm{M}-\mathrm{H}-2 \mathrm{Na}]^{-}$ & 78.7 & -5000 & -600 & -36 \\
\hline
\end{tabular}

*Quantitative ions are underlined 
of mobile phase, and buffer gradient was required for optimal retention. The highly hydrophilic pyrophosphates were well separated on a multi-modal C18 column with triethylamine (TEA) as an ion-pairing agent (Fig. 1).

Since the ion-pairing modifiers may interfere with the electrospray ionization (ESI) process, ${ }^{1-3}$ the TEA concentration was optimized under presence of $\mathrm{NH}_{4} \mathrm{HCO}_{3}$ to avoid ion suppression during both separation and MS detection in the negative ionization. Under the present eluant conditions (mobile phase A: $10 \mathrm{mM} \mathrm{NH}_{4} \mathrm{HCO}_{3}$ and $0.05 \%$ triethylamine in water; B: $0.1 \%$ triethylamine in $80 \%$ acetonitrile), chromatographic resolution was substantially improved all pyrophosphates separated within $10.0 \mathrm{~min}$. The disadvantage of ion-pairing chromatography is the long equilibrium times of the columns, but the multi-modal C18 column successfully achieved the high-throughput analysis because of its diversity in a stationary component containing anion and cation exchanges as well as the normal and reversed ligands.

In the mass spectrum, all pyrophosphates were mainly produced by the corresponding $[\mathrm{M}-\mathrm{H}]^{-},[\mathrm{M}-\mathrm{H}-\text { phosphate }]^{-}$,

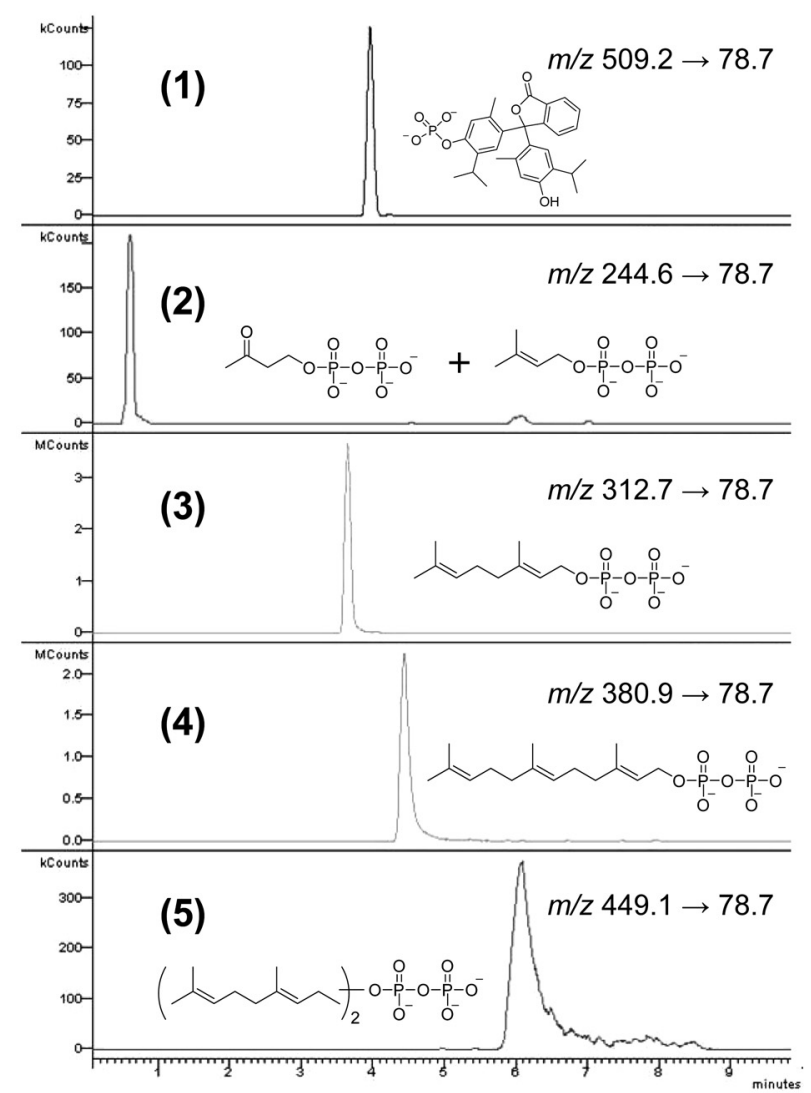

Figure 1. The LC-MS/MS chromatograms in the selected-reaction monitoring mode of the five pyrophosphates. (1) thymolphthalein monophosphate as an internal standard, (2) isopentenyl pyrophosphate and dimethylallyl pyrophosphate, (3) geranyl pyrophosphate, (4) farnesyl pyrophosphate, and (5) geranylgeranyl pyrophosphate. and [phosphate $]^{-}$ions. The MS/MS experiment used [M-H] ions as the precursor, which formed the phosphate ions as the base peaks. After getting the characteristic ions of individual pyrophosphates, the $\mathrm{S} / \mathrm{N}$ ratios and LOQ levels of each pyrophosphate in SRM and selected-ion monitoring analyses were compared with the QC samples. SRM analysis was chosen to monitor the pyrophosphates with both higher $\mathrm{S} / \mathrm{N}$ ratios and lower LOQ levels of the five pyrophosphates.

\section{Optimization of sample preparation}

Various techniques have been tested for sample preparation steps such as dilution and protein precipitation. These techniques include $\mathrm{pH}$ optimization and the use of co-solvents and complex agents. To develop these conditions, both the solubility of the analytes and the selection of a suitable membrane filter were considered during the sample preparation. Addition of miscible solvents such as methanol, acetone, and acetonitrile to the sample solution may cause protein precipitation. Therefore, methanol and acetonitrile were compared, and the recovery efficiency of pyrophosphates in methanol was observed to be better.

After the methanol dilution, we compared three different pH conditions: 1) Adjusted acidic condition ( $\mathrm{pH} 4.2$ ) with $0.1 \%$ formic acid in $\mathrm{MeOH}$; 2 ) Adjusted neutral condition (pH 7.2) with 0.2 M phosphate buffer; and 3) Adjust basic condition ( $\mathrm{pH} 10.5$ ) with $1 \% \mathrm{~K}_{2} \mathrm{CO}_{3}$ solution. The recovery efficiency was the best when $0.2 \mathrm{M}$ phosphate buffer for the neutral condition was employed. The solvation layer containing buffer and methanol was immediately deproteinized using an Ultrafree-MC with PVDF membrane with a $0.1 \mu \mathrm{m}$ pore size or a 3,000 Da molecular cut-off filter, ${ }^{14}$ and an UltrafreeMC with PVDF membrane with a $0.1 \mu \mathrm{m}$ pore size was used for $5 \mathrm{~min}$ at $14,000 \mathrm{rpm}$ at $4{ }^{\circ} \mathrm{C}$.

\section{Method validation}

Method validation requires an LOD, an LOQ, linearity, recovery, precision, and accuracy using QC samples. A calibration curve was generated for all analytes using the QC samples fortified with all reference standards at three different concentrations $(0.2,1$, and $5 \mu \mathrm{g} / \mathrm{mL})$ for the five pyrophosphates. Quantification was based on peak area ratios versus the ISTD. Calibration samples were prepared at eight different concentrations (each containing all five pyrophosphates). Least-squares regression analysis was performed on peak area ratios obtained at different concentrations to obtain the calibration curves. GPP and FPP had an LOQ of $0.05 \mu \mathrm{g} / \mathrm{mL}$, whereas IPP/DMAPP and GGPP had an LOQ of $0.1 \mu \mathrm{g} / \mathrm{mL}$. The devised method was found to be linear $\left(\mathrm{R}^{2}=0.9937-0.9992\right)$ over the dynamic ranges (LOQ $\sim 10 \mu \mathrm{g} / \mathrm{mL}$ each; Table 2).

Precisions and accuracies were determined by analysis of the prepared QC samples. The intra-day $(n=5)$ precision $(\% \mathrm{CV})$ was $2.9-12.3 \%$, while the accuracy (\% bias) was $89.6-111.8 \%$. The inter-day $(n=5)$ precision and accuracy was $4.7-9.4 \%$ and $91.4-104.2 \%$, respectively. The overall recoveries were $51.4-106.6 \%$ for the five pyrophosphates studied. 
Table 2. Validation results of intra- and inter-day assays for the five plasma pyrophosphates

\begin{tabular}{|c|c|c|c|c|c|c|c|c|c|}
\hline & \multicolumn{4}{|c|}{ Inter-day $(n=5)$} & \multicolumn{5}{|c|}{ Intra-day $(n=5)$} \\
\hline & $\begin{array}{l}\text { Conc. } \\
\text { (ig/mL) }\end{array}$ & $\begin{array}{c}\text { Precision } \\
(\% \mathrm{CV})\end{array}$ & $\begin{array}{l}\text { Accuracy } \\
\text { (\% bias) }\end{array}$ & $\begin{array}{c}\text { Precision } \\
(\% \mathrm{CV})\end{array}$ & $\begin{array}{c}\text { Accuracy } \\
\text { (\% bias) }\end{array}$ & $\begin{array}{c}\text { Recovery } \\
(\%)\end{array}$ & $\begin{array}{c}\text { IDL } \\
(\mu \mathrm{g} / \mathrm{mL})\end{array}$ & $\begin{array}{c}\text { LOD } \\
(\mu \mathrm{g} / \mathrm{mL})\end{array}$ & $\begin{array}{c}\text { LOQ } \\
(\mu \mathrm{g} / \mathrm{mL})\end{array}$ \\
\hline \multirow{3}{*}{ IPP/DMAPP } & 0.2 & 4.8 & 100.3 & 5.6 & 111.8 & 51.4 & 0.02 & 0.05 & 0.1 \\
\hline & 1 & 6.4 & 104.2 & 4.9 & 97.8 & 67.0 & & & \\
\hline & 5 & 7.1 & 102.9 & 7.8 & 106.5 & 56.4 & & & \\
\hline \multirow{3}{*}{ GPP } & 0.2 & 6.2 & 95.4 & 6.6 & 96.4 & 88.1 & 0.02 & 0.02 & 0.05 \\
\hline & 1 & 9.4 & 96.1 & 10.7 & 99.4 & 93.7 & & & \\
\hline & 5 & 8.1 & 101.6 & 9.2 & 106.7 & 92.6 & & & \\
\hline \multirow{3}{*}{ FPP } & 0.2 & 5.5 & 102.1 & 3.0 & 108.6 & 88.5 & 0.02 & 0.02 & 0.05 \\
\hline & 1 & 5.4 & 101.1 & 2.9 & 96.4 & 90.4 & & & \\
\hline & 5 & 6.3 & 95.1 & 10.4 & 103.4 & 106.6 & & & \\
\hline \multirow{3}{*}{ GGPP } & 0.2 & 8.0 & 100.0 & 12.3 & 100.9 & 83.9 & 0.02 & 0.05 & 0.1 \\
\hline & 1 & 4.7 & 91.4 & 1.9 & 89.6 & 94.0 & & & \\
\hline & 5 & 6.7 & 92.3 & 11.7 & 95.2 & 87.1 & & & \\
\hline
\end{tabular}

IDL, instrument detection limit; LOD, limit of detection; LOQ, limit of quantification; IPP/DMAPP, isopentenyl pyrophosphate/ dimethylallyl pyrophosphate; GPP, geranyl pyrophosphate; FPP, farnesyl pyrophosphate; GGPP, geranylgeranyl pyrophosphate

\section{Conclusion}

A method for the analysis of five pyrophosphates (IPP, DMAPP, GPP, FPP, and GGPP) in plasma samples was developed and validated. The devised method allowed chromatographic separation of five intermediates on the isoprenoid pathway for cholesterol synthesis using a multimodal C18 column for LC-MS/MS analysis. The isomeric compounds IPP and DMAPP are structurally similar except for the location of the carbon double bond. The LC method described here could not separate these isomers, and the concentrations of both IPP and DMAPP were calculated as the sum of the two analytes in the sample. This LC-MS/ MS-based method can be used to evaluate the levels of pyrophosphates in plasma and could be applicable to cardiovascular events related to cholesterol production.

\section{Acknowledgement}

This study was supported by an intramural grant from the Korea Institute of Science and Technology (KIST) and by the Converging Research Center Program through the Ministry of Education, Science and Technology (2011K000885).

\section{References}

1. Henneman, L.; van Cruchten, A. G.; Denis, S. W.;
Amolins, M. W.; Placzek, A. T.; Gibbs, R. A.; Kulik, W.; Waterham, H. R. Anal. Biochem. 2008, 383, 18.

2. Henneman, L.; van Cruchten, A. G; Kulik, W.; Waterham, H. R. Biochim. Biophys. Acta 2011, 1811, 227.

3. Jauhiainen, M.; Mönkkönen, H.; Räikkönen, J.; Mönkkönen, J.; Auriola, S. J. Chromatogr. B 2009, 877, 2967.

4. Bajad, S. U.; Lu, W.; Kimball, E. H.; Yuan, J.; Peterson, C.; Rabinowitz, J. D. J. Chromatogr. A 2006, 1125, 76.

5. Nürenberg, G.; Volmer, D. A. Anal. Bioanal. Chem. 2011, DOI 10.1007/s00216-011-5262-2.

6. Hooff, G. P.; Patel, N.; Wood, W. G.; Müller, W. E.; Eckert, G. P.; Volmer, D. A.; Anal. Bioanal. Chem. 2010, 398, 1801.

7. O’Neill, W. C.; Sigrist, M. K.; McIntyre, C. W. Nephrol. Dial. Transplant. 2010, 25, 187.

8. Tong, H.; Wiemer, A. J.; Neighbors, J. D.; Hohl, R. J. Anal. Biochem. 2008, 378, 138.

9. Saisho, Y.; Morimoto, A.; Umeda, T. Anal. Biochem. 1997, 252, 89.

10. Bicker, W.; Lämmerhofer, M.; Keller, T.; Schuhmacher, R.; Krska, R.; Lindner, W. Anal. Chem. 2006, 78, 5884.

11. Stevenson, P. G; Fairchild, J. N.; Guiochon, G. J. Chromatogr. A 2011, 1218, 1822.

12. Ha, Y. W.; Moon, J. Y.; Jung, H. J.; Chung, B. C.; Choi, M. H. J. Chromatogr. B 2009, 877, 4125.

13. Moon, J. Y.; Jung, H. J.; Moon, M. H.; Chung, B. C.; Choi, M. H. J. Am. Soc. Mass Spectrom. 2009, 20, 1626.

14. Pont, F.; Luciani, B.; Belmant, C.; Fournié, J. J. Anal. Chem. 2001, 73, 3562. 